\title{
ROBINSON, Lyn. Understanding healthcare information. London: Facet Publishing. 2010. ISBN 978-1-85604-662-6.
}

This book has a logical themed breakdown into chapters and my eyes were immediately drawn to final section entitled 'Afterword - keeping up to date'. This last section of the book emphasises that health information is never static and highlights sources for keeping up to date. One method is a blog linked to the book through which the authors encourage readers to contribute any changes, and this makes you feel like part of the process of keeping the resource current.

The book focuses on what information professionals and wider audiences need to know, rather than simply listing online resources which might go out of date quickly, and thus looks at the context within which information professionals may be working.

Topics covered in the book included the nature of healthcare knowledge, the historical context of healthcare information, and producers and users of this information. It then goes on to cover healthcare information sources, services and retrieval, and how this information is managed.

Recognition is given to the large number and wide range of sources of healthcare information, and how there are both formal and informal communication methods used to disseminate this information. The author discusses drives for change including, amongst other factors, scientific advances, increasingly multidisciplinary teams, increasing expenditure, an aging population and technological developments. She also highlight the increasing emphasis on individual choice and responsibility for healthcare which is starting to impact on how healthcare information is provided.

An interesting aspect covered by the book is that of an increasing number of methods for studying healthcare information behaviour, looking at what people do with this information. This includes questionnaires, ethnography and interviews. Consumers of healthcare information are an increasingly important group, and one that producers of healthcare information need to remember. These changes are placed in the context of the age-old problem of how people access this information, facing issues such as lack of easy access or time to consult sources, or lack of knowledge about the appropriateness of a resource. This leads the author onto discussing the challenging consideration of how to assess the impact of information provision, what people are doing with the information once they have access to it.

I was interested in reviewing this book as a university subject librarian who has recently taken over responsibility for health courses as part of my remit. So it was through these eyes which I read the book. I found it very useful in giving me the 
historical and wider perspective on healthcare information, into which I can place my specific context. However, I believe the book is relevant to a wide range of professionals, whether those in an information or knowledge management role, or healthcare professionals themselves. Knowing the wider context within which we operate is essential, and I believe this book provides a balanced insight into this key subject.

\section{Suzie Kitchin}

Library Liaison Adviser, Northumbria University suzie.kitchin@northumbria.ac.uk 